\title{
Compartimentação do relevo no município de Manoel Viana - RS
}

\author{
Subdivision of the relief in Manoel Viana municipally - RS
}

\author{
Anderson Augusto Volpato Sccoti', Luis Eduardo de Souza Robaina² e Romário Trentin ${ }^{3}$ \\ 1,2,3 Laboratório de Geologia Ambiental (LAGEOLAM-UFSM)
}

\begin{abstract}
Resumo
O Município de Manoel Viana localiza-se na região oeste do Rio Grande do Sul, na bacia do rio Ibicui, a uma distância de 500 km da capital Porto Alegre. As litologias predominantes no município estão ligadas as rochas sedimentares das Formações Botucatu e Guára, Vulcânicas da Formação Serra Geral e depósitos Fluviais junto as principais drenagens. O relevo classifica-se, predominantemente, como suavemente ondulado com altitudes que predominam entre $80 \mathrm{~m}$ e $180 \mathrm{~m}$, em relação ao nível do mar. A menor cota altimétrica encontra-se ao nível de $60 \mathrm{~m}$, junto à planície do Rio Ibicuí e a maior cota é de 240m, tendo assim uma amplitude altimétrica de $180 \mathrm{~m}$. Na região Nordeste de Manoel Viana, encontram-se as porções mais elevadas do relevo e a formação de vertentes escarpadas. O intervalo de declividade, predominante, é o $<2 \%$, totalizando mais da metade área de estudo $56 \%$, distribuindo-se em todas as altitudes, sendo característicos dos relevos de planícies, nos amplos interflúvios e no topo dos morros e morrotes. As formas de relevo podem ser classificadas como: rampas de fundo de vale caracterizadas por apresentar declividade menor que $2 \%$, ocorrendo junto das principais drenagens; as formas de colinas levemente onduladas caracterizadas por vertentes com comprimentos amplos e declividade entre 2 e $5 \%$; as formas de colinas fortemente onduladas, caracterizadas por declividades entre 5 e 15\% que ocorrem em uma área de transição entre dois patamares de dissecação; os morrotes isolados caracterizados por amplitudes inferiores a $100 \mathrm{~m}$ e vertentes íngremes, constituindo porções mais resistentes aos processos erosivos; associado aos morrotes, as formas de cornijas, que são camadas de rochas sedimentares resistentes que mantém uma forma de degrau na meia encosta das colinas e; as formas de morros e morrotes, associados a colinas fortemente onduladas, que se caracterizam por encostas com declividades superiores a 15\%, ocorrendo na transição do primeiro para um segundo patamar de dissecação.
\end{abstract}

Palavras Chave: Hipsometria; Declividade; Análise de Vertente; Unidades de Relevo; Oeste do RS.

\begin{abstract}
The Manoel Viana municipality is located in western Rio Grande do Sul, in Ibicui River Basin. The altitudes are among the range of $80 \mathrm{~m}$ and $120 \mathrm{~m}$ above the sea level, corresponding to $46 \%$ of the total altitude, and $120 \mathrm{~m}$ and $180 \mathrm{~m}$ above the sea level, which has approximately $49 \%$ of the total. The lowest altitude is approximately $60 \mathrm{~m}$ and it is along the plain of the Ibicuí river, and the highest altitude is approximately $240 \mathrm{~m}$, in the northeast region of Manoel Viana. The predominant declivity distance is less of $2 \%$, with more than half the study area $56 \%$, distributed at all altitudes, being characteristic of the plain reliefs, the broad interfluves and the tops of hills and hillock. The landforms can be classified as: ramps of valley bottom characterized by presenting a slope less than $2 \%$ occurring among the major drainages; forms of gently rolling hills with slopes between $2 \%$ and $5 \%$ and wide lengths; forms of strongly wavy hills characterized by slopes between 5 and $15 \%$ that occur in the transition area between two levels of dissection; isolated mounts characterized by amplitudes lower than 100m and steep slopes, associated with the most resistant portions to erosion; and associated to mounts, forms of hills which are called sedimentary rocks from the formation of Guará and Botucatu; the forms of mounts and hills associated to the strongly wavy hills, which characterize by slopes greater than $15 \%$, occurring the transition of the first to a second level of dissection.
\end{abstract}

Keywords: Hypsometry; Slope; Analysis of slope; Relief Units; West RS 


\section{INTRODUÇÃO}

As formas de relevo são o resultado dos agentes modeladores da superfície, tanto internos como externos, e se apresentam como objeto de estudo da Geomorfologia, tanto nos aspectos de gênese como da evolução destas formas, com velocidades variadas, interagindo, a todo instante, com os demais componentes da paisagem.

Conforme Ab'Saber (1969), a compartimentação topográfica apresenta uma dimensão muito maior que a própria denominação, uma vez que transcende a ideia de topografia no que tange aos aspectos morfológicos e morfométricos do relevo, resultantes das propriedades adquiridas durante sua gênese e evolução.

Segundo Guerra \& Cunha (1998, pág. 24), o relevo sempre teve uma forte ligação com as atividades do homem, "no sentido de lhe conferir grande importância em muitas situações do seu dia-dia, como para assentar moradias, estabelecer melhores caminhos de locomoção, localizar seus cultivos, criar rebanhos e definir seus domínios".

No município de Manoel Viana, os processos de dinâmica superficiais associados a erosões aceleradas, como arenização e voçorocas, são muito significativos e exigem o conhecimento da paisagem para sua compreensão.

Dessa forma, o presente artigo pretende contribuir com estudos no município através da caracterização do relevo.

Manoel Viana está localizado na fronteira oeste do estado do Rio Grande do Sul (figura 1), entre as coordenadas de latitude $29^{\circ} 08^{\prime} 10^{\prime \prime} \mathrm{S}$ e $29^{\circ} 46^{\prime} 49^{\prime \prime} \mathrm{S}$

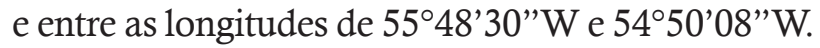

\section{FUNDAMENTAÇÃO TEORICO-METODO- LOGICA}

A cartografia de relevo, segundo Ross (1992), pode ser representada através do mapeamento taxonômico das sucessivas feições presentes na paisagem. A abordagem trazida pelo autor representa uma subdivisão do terreno em diferentes níveis escalares de compartimentação, desde o morfoestrutural até as feições das vertentes, prevendo a aplicação dos conhecimentos no planejamento e gestão do território.

O presente trabalho utiliza a metodologia proposta por Ross (1992), que diz respeito ao terceiro nível taxonômico, onde se define as unidades morfológicas ou de padrões de formas semelhantes, bem como De Nardin (2009) e Robaina et al. (2009) que utilizam unidades de relevo para zoneamento geoambiental.

Para a compartimentação do relevo do município de Manoel Viana, utilizaram-se as cartas topográficas do exército e imagens de satélite disponibilizadas pelo Google Earth. As cartas topográficas utilizadas são do serviço geográfico do exército, escala 1:50.000, do Arroio Piraju, folha: SH. 21-X-C-III-4; Caraguatai, folha: SH.21-X-D-I-3; Chalé, folha: SH.21-X-C-III-3; Passo do Goulart, folha: SH.21-X-D-I-1; Passo Novo, folha: SH.21-X-C-VI-2; Manoel Viana, folha: SH.21-X-D-IV-1 e Três Bocas, folha: SH.21-X-C-III-2.

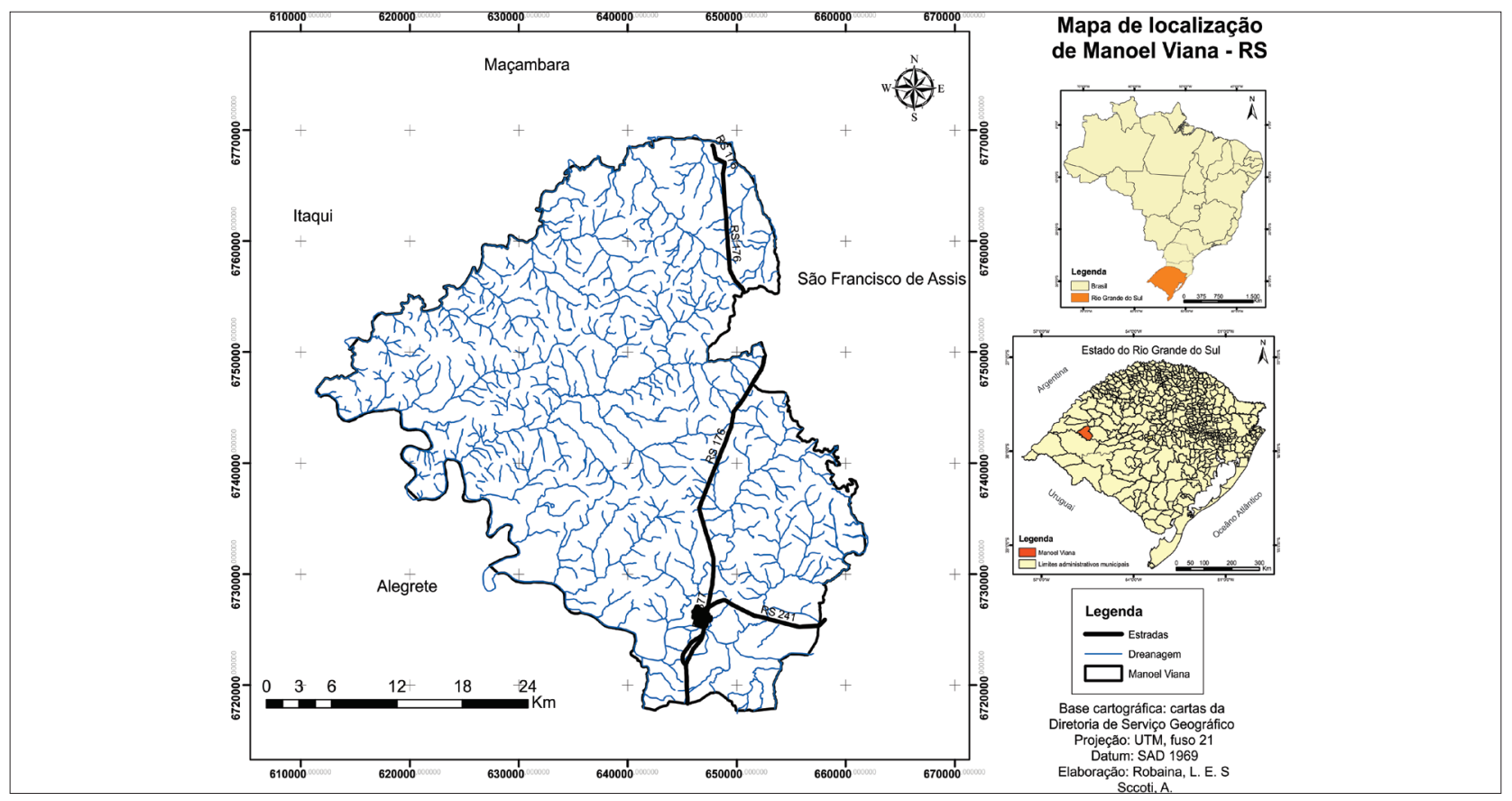

Figura 1. Localização do município de Manoel Viana no estado do Rio Grande do Sul. 
As classes da carta hipsométrica foram elaboradas através das rupturas no relevo, identificadas a partir da distribuição espacial das curvas de nível e dos reconhecimentos de campo. Foram utilizados os seguintes limites: menor que 80 metros, 80 - 120 metros, 120 - 180 metros e maior que 180 metros.

A carta de declividade se baseou na metodologia apresentada por Trentin (2007 pág. 42) que utilizou os intervalos de 2,5 e 15 onde: as áreas até $2 \%$ de inclinação correspondem a áreas muito planas com baixa capacidade de drenagem e quando próximas às drenagens estão sujeitas à ocorrência de inundações; o intervalo de 2 a 5\% com predomínio de processos de acumulação e meteorização; intervalo de 5 a 15\% quando os processos de transporte de massa passam a ser significativos e; intervalo superior a $15 \%$ onde processos de movimento de massa podem ocorrer especialmente pela necessidade de cortes e aterros.

O SIG (sistema de informações geográficas), utilizado para a interpolação dos dados e construção do mapa de unidades do relevo, foi o Spring versão 4.3.3 desenvolvido pelo Instituto de Pesquisas Espaciais (INPE). Para análise das vertentes, construíram-se perfis topográficos usando o ArcGis versão 10 desenvolvido pela ESRI.
Para definição das formas de relevo, usou-se como base a proposta apresentado pelo IPT (Instituto de Pesquisas Tecnologicas) (1981) que define rampas, colinas, morrotes e morros.

Os mapas do relevo são produtos que podem ser gerados a partir do Modelo Numérico do Terreno (MNT), que é uma das técnicas de geoprocessamento que permitem representar uma grandeza que varia continuamente no espaço. Esse modelo apresentado no presente trabalho foi criado no programa Spring versão 4.3 .3 a partir da digitalização das curvas de nível e pontos cotados.

\section{RESULTADOS OBTIDOS}

O município de Manoel Viana apresenta características comuns aos municípios da fronteira oeste do Rio Grande do Sul, como vastas áreas de campo, solos frágeis (vulneráveis a processos erosivos acelerados) e uma grande área territorial, tendo como produto dessa variação uma diversificação de modelados de relevo.

O relevo no município de Manoel Viana caracteriza-se por estar dividido em dois patamares, limitados por uma linha de escarpa que se encontra na cota de $180 \mathrm{~m}$ acima do nível do mar.

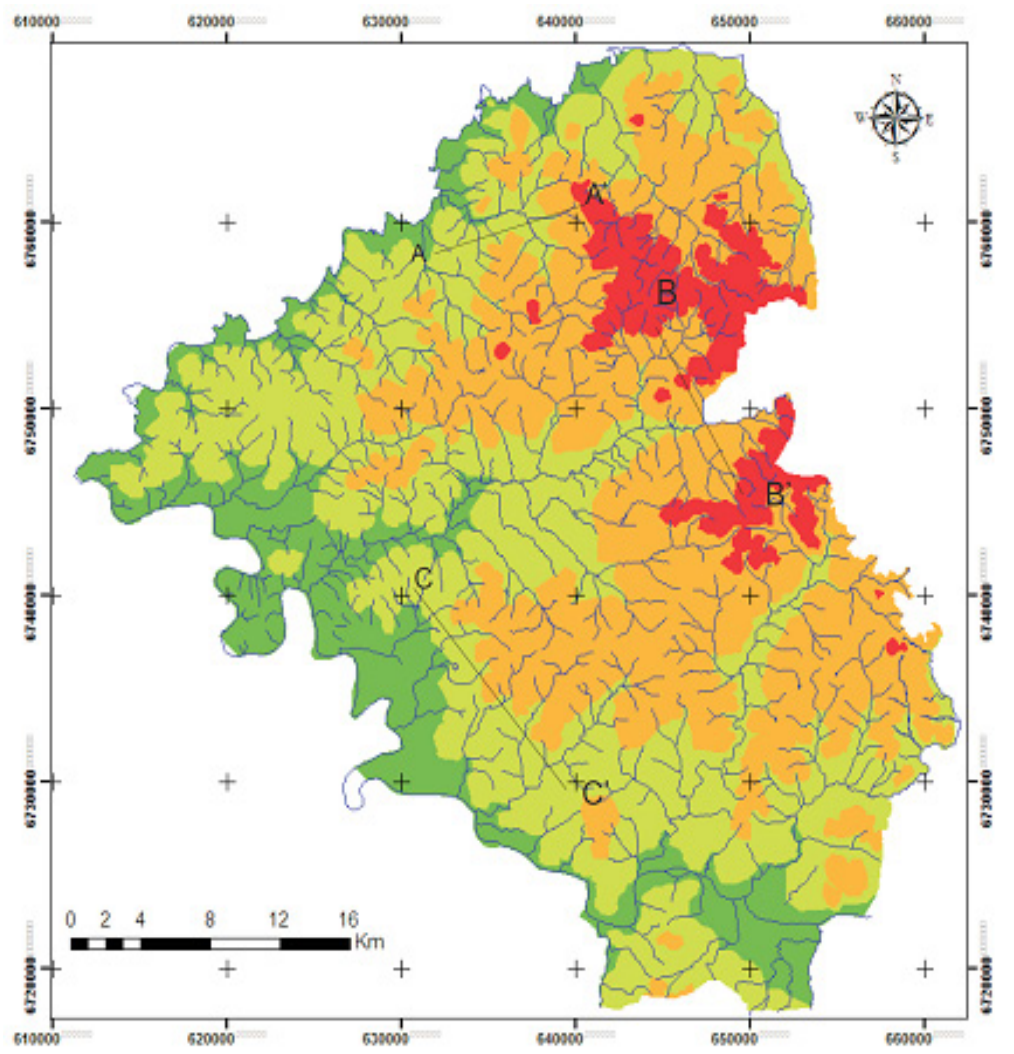

\section{Mapa Hipsométrico de Manoel Viana}

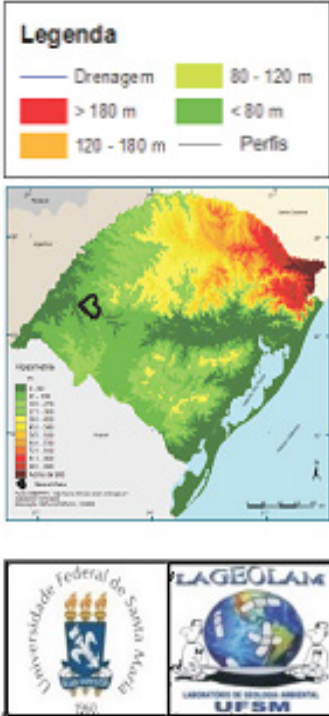

Esse cartogrifica catas da Diesáo de Striço Geográleo (DSC) Ditum: SAD 1969 Projeç ba UTM, zona 21 . SCCON, A ; TRENTN, R

Figura 2. Mapa hipsométrico de Manoel Viana 


\section{I. Análise Hipsométrica}

O município de Manuel Viana apresenta como menor cota altimétrica o nível de 60 metros, junto à planície do Rio Ibicuí. A maior cota é de 240 metros, resultando em uma amplitude altimétrica de 180 metros, o que representa uma significativa energia do relevo na área de estudo.

A figura 2 apresenta o mapa hipsométrico de Manoel Viana, onde são discriminadas 4 classes hipsométricas: < 80m; 80-120m; 120-180m; >180m. No mapa, estão localizados os perfis topográficos A-A'; B-B' e C-C'.

As altitudes predominantes encontram-se entre o intervalo de 80 a $120 \mathrm{~m}$ e de 120 a $180 \mathrm{~m}$, correspondendo, respectivamente, a $46 \%$ da área e $49 \%$ do total. As porções menores de $80 \mathrm{~m}$ limitamse as margens do Ibicui, adentrando as planícies do Arroio Piraju e demais arroios conforme mostrado no mapa.

As altitudes superiores a $180 \mathrm{~m}$ encontram-se na porção leste do município, sendo constituídos predominantemente por áreas de divisores de água, com vertentes íngremes que delimitam bacias hidrográficas que drenam o município.

\subsection{Análise das vertentes}

As vertentes são analisadas através dos seus atributos como amplitude, comprimento, forma e declividade. Os atributos são observados através da análise dos perfis A-A'; B-B' e C-C' localizados na (figura 2).

O perfil A-A' (figura 3) apresenta o recorte transversal de sudoeste para nordeste, seguindo o aumento das altitudes. O relevo nas menores altitudes apresenta vertentes planas a levemente onduladas (1), convexas, com amplitude altimétrica variando entre $20 \mathrm{~m}$ e $40 \mathrm{~m}$ e comprimento ao redor de $1000 \mathrm{~m}$. Na porção nordeste, observa-se uma pequena escarpa(2), formando um degrau no terreno com $40 \mathrm{~m}$ de amplitude que marca uma quebra de relevo, gerada pela diferença na resistência do substrato litológico e isso marca as porções onde está ocorrendo os processos de desgaste do planalto basáltico.

\section{Perfil (A-A')}

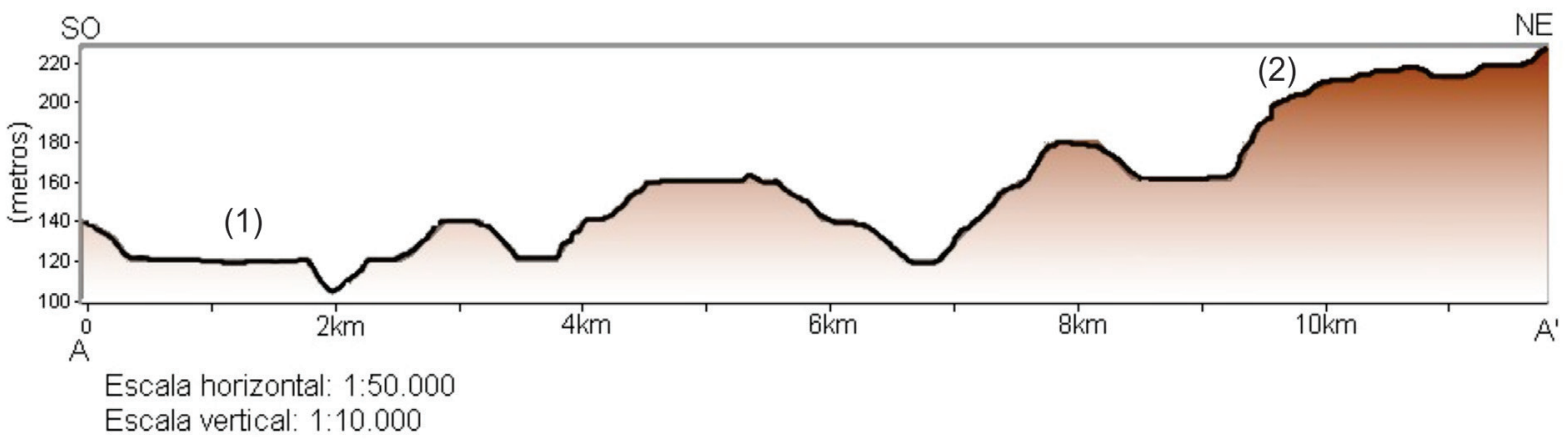

Figura 3. Perfil A-A' mostra um corte na parte norte do município de direção N35E.

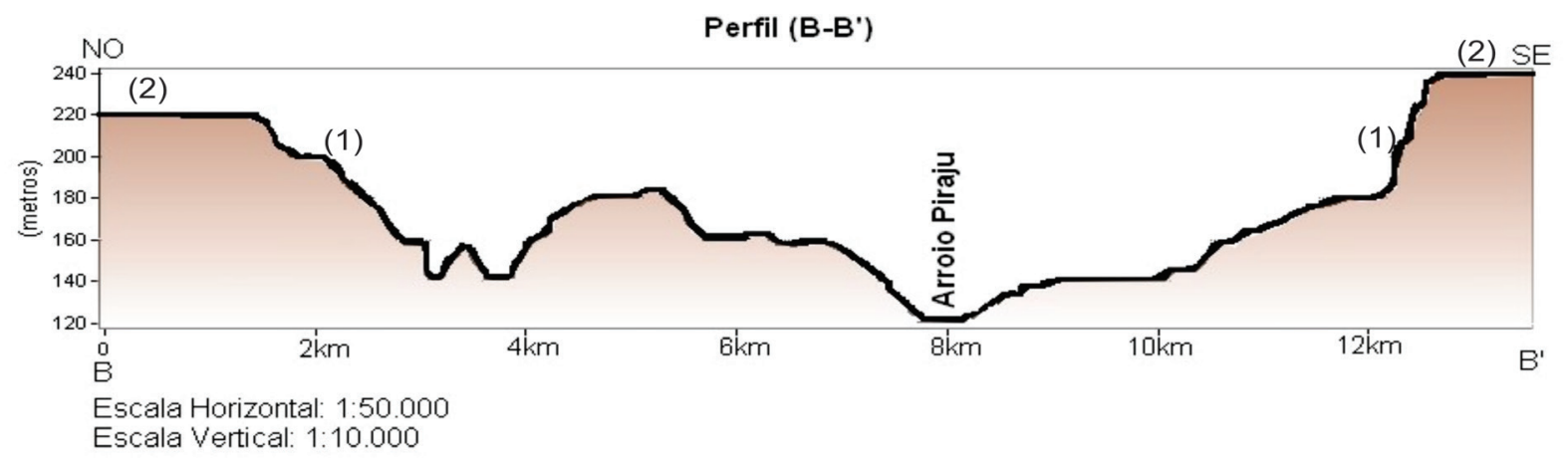

Figura 4. Perfil B-B' mostra um corte na parte leste do município de direção N15W. 


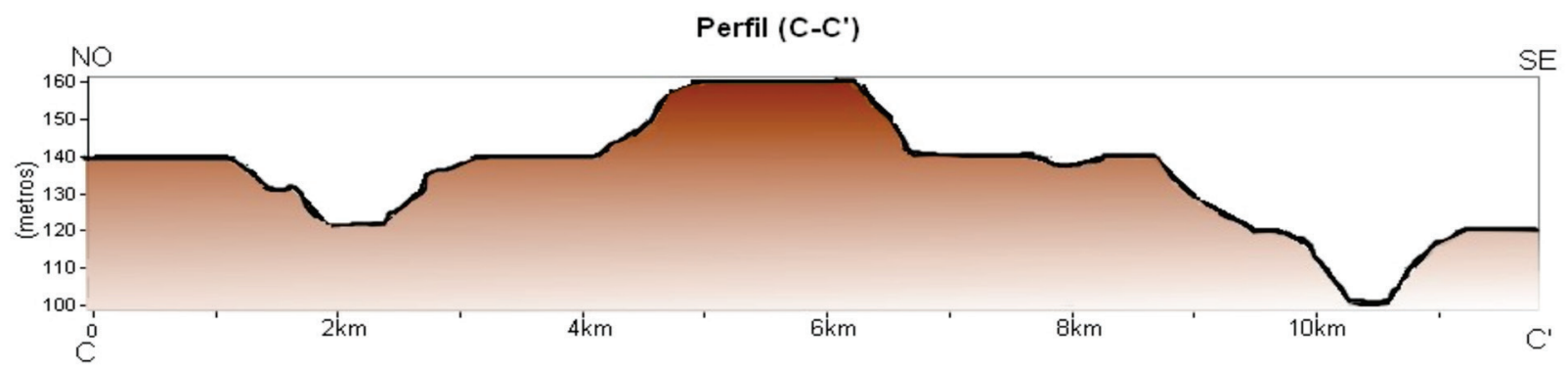

Escala Horizontal: 1:50.000

Escala Vertical: 1:10.000

Figura 5. Perfil C-C' mostra um corte na porção oeste do município de direção N30W.

O perfil B-B' (figura 4) de noroeste a sudeste, na parte leste do município, corta uma das principais drenagens do município, o arroio Piraju, que forma um vale encaixado em lineamentos estruturais. Apresenta um relevo fortemente ondulado com vertentes escarpadas de amplitudes ao redor de $60 \mathrm{~m}$. No topo das áreas escarpadas, há ocorrência de um relevo plano com declividades entre 2 e $5 \%$ e altitudes superiores a $200 \mathrm{~m}$.

No perfil C-C' (figura 5) de direção noroeste para sudeste, na porção oeste do município, observa-se um relevo levemente ondulado de vertentes convexas com amplitudes altimétricas entre $20 \mathrm{~m}$ a $40 \mathrm{~m}$, comprimentos entre 1000 e $2000 \mathrm{~m}$ e com vales amplos.
A análise das declividades do município permite caracterizá-lo em seu conjunto como uma área levemente ondulada (figura 6). O intervalo de declividade predominante é o menor de $2 \%$, totalizando mais da metade da área de estudo $56 \%$. Este intervalo de declividade distribui-se em todas as altitudes, sendo característicos dos relevos de planícies, nos amplos interflúvios e no topo dos morros e morrotes. Nas áreas rebaixadas topograficamente, os processos de acumulação e meteorização são os mais significativos.

As declividades entre 5 a $15 \%$, que na área de estudo ocorrem em $19 \%$ da área total, representam os locais onde os processos erosivos passam a atuar mais intensamente gerando importantes

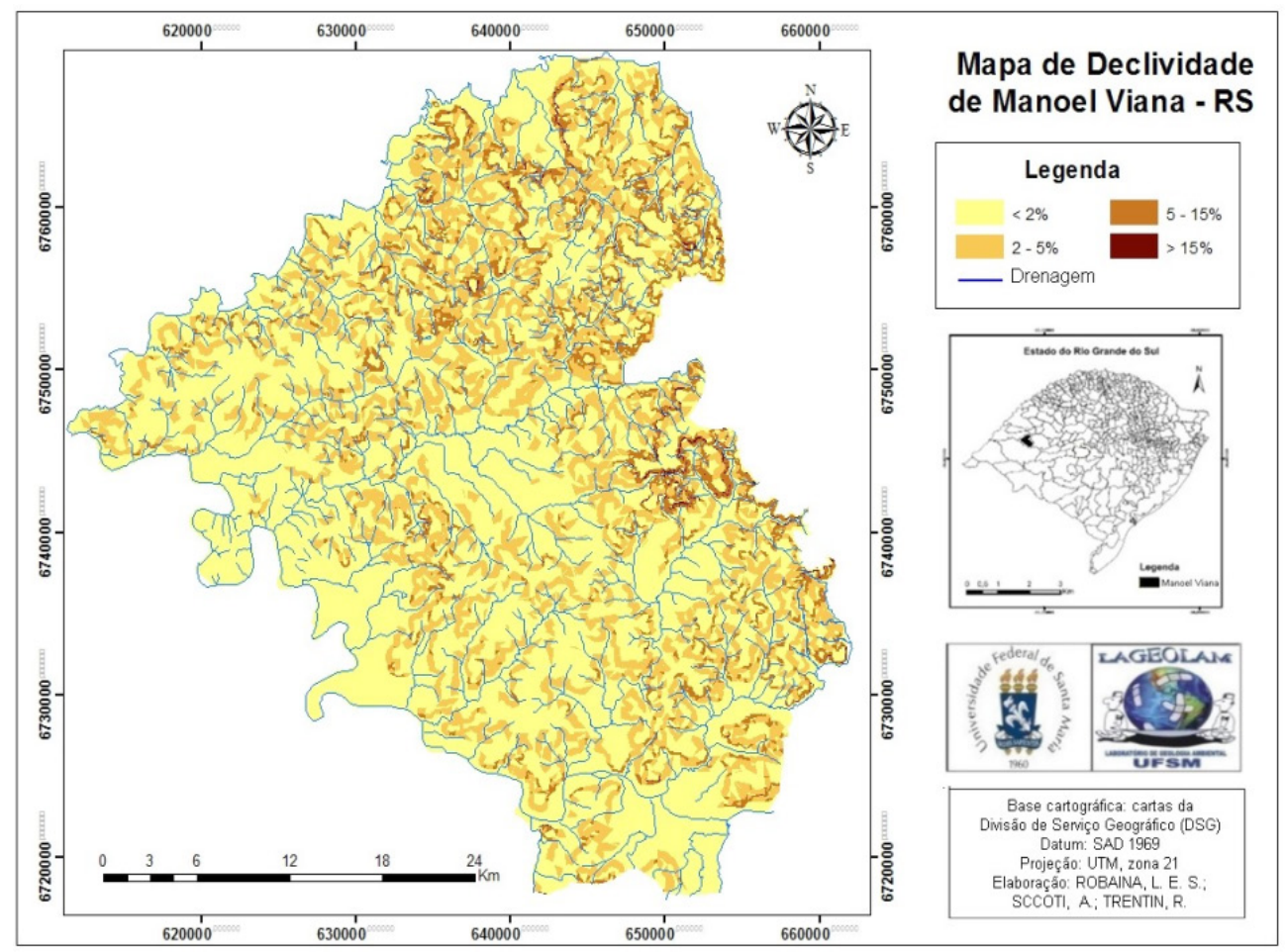

Figura 6. Mapa de declividade de Manoel Viana. 
feições superficiais de areais e voçorocas, que são processos naturais porém, potencializados por ações antrópicas.

As declividades superiores a 15\% representam as áreas de maior inclinação, marcando uma importante ruptura do relevo.

\subsection{Unidades do relevo}

Através da análise dos parâmetros morfométricos do relevo, definiu-se as unidades morfológicas ou de padrões de formas semelhantes no Município de Manoel Viana, apresentado no mapa da figura 7.

O relevo de Manoel Viana caracteriza-se pela existência de dois patamares de dissecação, separados por uma área de escarpa. Essa transição encontra-se a nordeste do município, ao redor da cota de $180 \mathrm{~m}$.

O primeiro patamar localizado na porção superior corresponde a $4 \%$ do total da área do município e apresenta altitudes superiores a $180 \mathrm{~m}$ com formas de relevo de colinas suaves de altitude que se caracterizam por declividades predominantemente, entre $2 \%$ e $5 \%$. Ainda se encontram as cabeceiras de drenagem que formam áreas úmidas em forma de anfiteatro.
A transição para o patamar inferior ocorre através de um degrau formando escarpas associadas a um relevo de morros e morrotes. Nessas áreas. O relevo é marcado por formas abruptas, as declividades ultrapassam os $15 \%$ e são áreas onde as florestas nativas são relativamente bem preservadas, pois mantém suas características naturais, são locais de difícil acesso para que sejam exploradas. No município de Manoel Viana, as escarpas marcam uma "faixa" ao redor do segundo patamar de dissecação.

$\mathrm{O}$ segundo patamar está representado em 96\% do município de Manoel Viana, com altitudes inferiores a 180 metros, formando as seguintes unidades de relevo: rampas de fundo de vale, colinas levemente onduladas, colinas fortemente onduladas.

A unidade, definida como rampas de fundo de vale, corresponde a $12 \%$ da área total do município, se caracteriza por apresentar encostas com declividade menor que $2 \%$, constituindo as planícies de inundação, onde em épocas de maior precipitação o rio pode avançar sobre essas áreas deixando, assim, parte alagado.

As colinas levemente onduladas são áreas que apresentam uma declividade entre 2 e $5 \%$ e amplitudes ao redor de $40 \mathrm{~m}$ e perfis convexo com amplos interflúvios. Essa unidade de relevo é a que

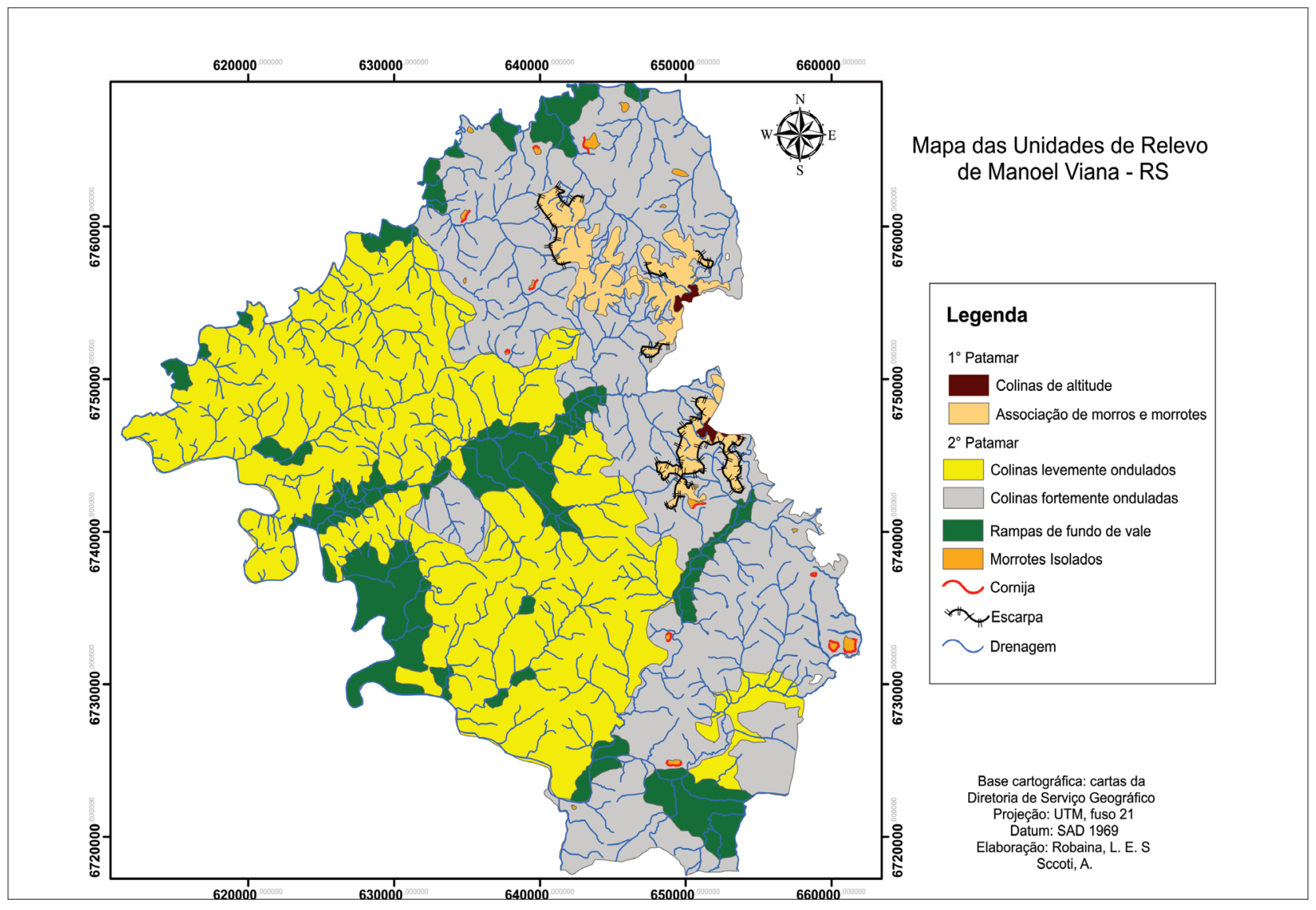

Figura 7: mapa das unidades de relevo de Manoel Viana. 
predomina no município, correspondendo a $42 \%$ da área total, caracterizando o relevo de "coxilias" da campanha gaúcha, essa esculturação pode estar ligada a resistência do substrato litológico.

$\mathrm{Na}$ unidade de colinas fortemente onduladas, as declividades ficam entre 5 e 15\% são caracterizadas por áreas com relevo mais movimentado, onde processos erosivos são importantes

A unidade de morrotes isolados se caracteriza por elevações de amplitudes ao redor de $40 \mathrm{~m}$ e vertentes com inclinações acima de $15 \%$. Elas representam os indícios da dissecação que o relevo sofreu com o passar do tempo, ou seja, marcam uma evolução do relevo sobre rochas, sedimentares com cimentos que lhes confere resistência (sílica ou óxido de ferro) ou de origem vulcânica, com diferentes resistências aos processos erosivos.

Associado a esses morrotes, estão as cornijas, que são camadas de rochas (sedimentares com cimento que lhe agrega resistência ou vulcânicas) relativamente mais resistentes aos processos erosivos e se formam a partir de erosão diferencial saliências com uma forma abrupta na meia vertente de colinas tanto onduladas como suaves.

\section{CONCLUSÕES}

A metodologia empregada mostrou-se eficiente, pois possibilitou a compartimentação do relevo no município de Manoel Viana.

Foram definidas através de análises morfométricas seis unidades de relevo encontradas em dois patamares de dissecação.

Os parâmetros de relevo representam importantes fatores condicionantes aos processos de dinâmica superficiais, permitindo, deste modo, levantamento fundamentais na definição de atividades de planejamentos.

Dessa forma, o presente trabalho apresenta informações básicas para trabalhos futuros de compartimentação geomorfológico e geoambientais no município de Manoel Viana-RS.

\section{REFERÊNCIAS BIBLIOGRAFICAS}

AB'SABER, A. N. Um conceito de geomorfologia a serviço das pesquisas sobre o quartenário.

Geomorfologia, São Paulo, Instituto de Geografia USP, n.19, p, 1-23, 1969.

DE NARDIN, D. Zoneamento geoambiental no oeste do Rio Grande do Sul: um estudo em bacias hidrográficas. Porto Alegre : UFRGS/PPGEA, 2009.

GUERRA, A. J. T.; CUNHA, S. B.(org).

Geomorfologia: uma atualização de bases e conceitos. Rio de Janeiro: Bertrand Brasil. 1998.

IPT. Mapeamento geomorfológico do Estado de São Paulo. São Paulo. Escala 1:500.000. (IPT publicações, 1183) 1981.

ROBAINA, L. E. S.; TRENTIN, R.; NARDIN, D.; CRISTO, S. S. V. Métodos e Técnicas Geográficas utilizadas na Análise e Zoneamento Ambiental. Geografias (UFMG), v. 05, p. 36-49, 2009.

ROSS, J. L. S. Registro cartográfico dos fatos geomórfológicos e a questão da taxonomia do Relevo. Revista da Pós-Graduação de USP, São Paulo, n.6, 1992.

TRENTIN, R. Definição de unidades geoambientais na bacia hidrográfica do rio Itu oeste do RS. Santa Maria: UFSM/PPGEO, 2007. 110 f. (Dissertação de Mestrado). 